\title{
O impacto das concepções de desenvolvimento infantil nas práticas pedagógicas em salas de aula para crianças menores de três anos
}

\author{
Janaina Cassiano Silva*
}

Alessandra Arce Hai ${ }^{* *}$

\section{Resumo}

Este artigo analisa o impacto que a concepção de desenvolvimento infantil traz para a prática pedagógica com crianças de zero a três anos à luz da Psicologia HistóricoCultural. Para tanto, traremos os resultados de uma pesquisa que investigou se as açóes educativas promovem o cuidar e o educar, associação imprescindível para a promoção do desenvolvimento psicológico das crianças menores de três anos. Para facilitar, subdividimos o trabalho em três partes, uma dedicada à apresentação da metodologia e caracterização das instituiçóes, outra para análise das práticas pedagógicas, e uma destinada à reflexão acerca da concepção de desenvolvimento que perpassa essas práticas à luz da Psicologia Histórico-Cultural. As práticas educativas desenvolvidas nas instituiçóes pesquisadas apenas aguardam o desenvolver considerado natural às crianças, afastando-se de uma Educaçáo Infantil que favoreça o desenvolvimento integral da criança em suas máximas potencialidades por meio do ensino como uma forma intencional de promovê-lo.

Palavras-chave: Práticas educativas. Desenvolvimento da criança. Psicologia Sociohistórica.

\footnotetext{
* Doutoranda em Educação no Programa de Pós-Graduação em Educação da Universidade Federal de São Carlos (PPGE/UFSCar). Bolsista da Fundação de Amparo à Pesquisa do Estado de São Paulo.

** Doutora em Educação Escolar pela Universidade Estadual Paulista Júlio de Mesquita Filho (Unesp). Professora adjunta do Centro de Educaçáo e Ciências Humanas $(\mathrm{CECH})$ da Universidade Federal de São Carlos (UFSCar).
} 


\section{Introdução}

Este artigo apresenta um estudo acerca do impacto que a concepção de desenvolvimento infantil traz para a prática pedagógica com crianças de zero a três anos à luz dos preceitos teóricos da Psicologia Histórico-Cultural. Para tanto, traremos os resultados obtidos na pesquisa de mestrado ${ }^{1}$ que investigou se as ações educativas estão promovendo o cuidar e o educar, considerando esta ligação imprescindível para a promoção do desenvolvimento psicológico das crianças menores de três anos. As conclusôes são produto de uma avaliação que associou a observação das práticas educativas de duas instituiçóes de Educação Infantil de uma cidade do interior do Estado de São Paulo (uma municipal e outra particular) com as análises das concepçóes de infância, de educador e do conhecimento presentes nos documentos oficiais do Ministério da Educação para a Educação Infantil e dos projetos político-pedagógicos das duas instituiçốes pesquisadas.

Desta forma, visando a contribuir para o debate sobre o papel que a Educação Infantil deve exercer na formação das crianças, apresentaremos uma problematização acerca das práticas pedagógicas e da concepção de desenvolvimento infantil presente nessas práticas segundo os pressupostos da Psicologia Histórico-Cultural.

É conveniente destacar que, nessa vertente, o educador assume a função de mostrar às crianças os traços da atividade humana, sustentados nos objetos da cultura, transmitindo a elas os resultados do desenvolvimento histórico (SAVIANI, 2005). Destarte, a participação do professor como agente ativo do processo de ensino-aprendizagem da criança é crucial, pois este não é um mero mediador no processo de aprendizagem da criança pequena. Ao contrário, trata-se de uma perspectiva do desenvolvimento infantil que contempla aspectos históricos e sociais da criança, e não apenas os fatores biológicos, ressaltando que este é um processo histórico-dialético (VIGOTSKY, 1995; LEONTIEV, 1978; ELKONIN, 1987). Temos em vista que, ao utilizarmos os pressupostos da Psicologia Histórico-Cultural, poderemos contribuir para a formação integral das crianças, respeitando a faixa etária e as características peculiares da infância.

Para facilitar a compreensão, subdividimos este artigo em quatro partes, sendo a primeira dedicada à apresentação dos procedimentos metodológicos, a segunda destinada à caracterização das duas instituiçóes. Já na terceira, 
realizaremos uma análise das práticas pedagógicas desenvolvidas. E, por fim, trabalharemos com a concepção de desenvolvimento que perpassa essas práticas, fazendo uma análise à luz da Psicologia Histórico-Cultural.

\section{Procedimentos metodológicos}

A natureza de uma investigação como a que nos propomos exige um cuidado com as informaçôes a serem coletadas, já que observar o dia a dia das práticas educativas significa sempre uma percepção das açóes explícitas dos agentes, mas também daquelas outras interpretaçóes que podemos realizar subsidiadas pelos elementos significativos que verificamos ao analisar os dados.

Selecionamos duas instituiçóes de Educação Infantil em uma cidade do interior do Estado de São Paulo, uma de iniciativa municipal e outra particular, considerando que estas poderiam apresentar dinâmicas diferentes quanto às práticas desenvolvidas. Algumas questóes nortearam esta opção feita: haveria diferenças no atendimento ofertado pela escola municipal em relação ao ofertado pela escola privada? Em havendo diferenças, em que estas consistiriam?

Os indivíduos estudados foram crianças que frequentam creches (crianças de zero a três anos), faixa etária cujos estudos direcionados ainda são escassos. O motivo dessa escassez se deve à história do atendimento nessas instituições, por muito tempo considerado como um mal necessário, ou seja, um local com a função única de substituir o trabalho das mães que não podiam cuidar de seus filhos em casa. Acrescente-se a esse fato que a criança menor de três anos tem maior necessidade de cuidados pessoais do que a criança de quatro a seis, já que o bebê, por exemplo, é completamente dependente do adulto que toma conta dele. Assim, entendemos que estudar o cotidiano das instituições que atendem crianças de zero a três anos se constitui não só um desafio, mas, sobretudo, uma necessidade, caso desejarmos pensar a educaçáo e o cuidado para além da simples guarda.

A seleção da instituição municipal foi encaminhada por intermédio da Secretaria de Educação (SME) de um município do interior do Estado de São Paulo, que indicou um Centro de Educação e Recreação $(\mathrm{CER})^{2}$ para a realização da pesquisa. Quanto à instituição particular, fizemos a escolha pela adesão ao estudo. 


\section{Procedimento para a coleta de informações}

O procedimento de coleta de dados foi baseado na observação (BOGDAN; BIKLEN, 1994). Inicialmente, visitamos as instituiçóes para expor o trabalho e nos familiarizarmos com os objetos de pesquisa. Vale salientar que, no preparo das observaçóes, segundo Bogdan e Biklen (1994), a primeira tarefa é a delimitação do objeto de estudo, que definimos como as atividades que as educadoras desenvolviam com as crianças.

Não utilizamos um roteiro previamente definido para a coleta dos dados, apenas tentamos observar o cotidiano das instituiçóes de Educação Infantil selecionadas. Contudo, utilizamos algumas categorias para centrar a nossa observação, com base em Gariboldi (2003), a saber:

- o espaço: o cenário em que se desenvolve a situação social;

- os participantes: as pessoas que estão presentes e atuam no contexto da instituição infantil;

- as atividades: as açóes desenvolvidas pelos participantes;

- os agrupamentos: as modalidades com que os participantes se agrupam na representação das açóes, classificadas em atividades de grupo, pequenos grupos, livres agregaçóes e tarefa individual;

- as modalidades de gestão: os modos escolhidos pelo professor para dirigir as representaçôes das crianças.

Optamos por registrar as observaçóes no formato de notas de campo, que significam "[...] o relato escrito daquilo que o investigador ouve, vê, experiencia e pensa no decurso da recolha e refletindo sobre os dados de um estudo qualitativo" (BOGDAN; BIKLEN, 1994, p. 150). Vale destacar que, na transcrição das informaçóes nas instituiçóes, focalizamos o que seria relevante ao nosso estudo.

Nas duas instituiçóes, foram realizadas quatro observaçóes em cada turma. Na instituição particular, esses acompanhamentos ocorreram no período da tarde, uma vez que, para a faixa etária pesquisada, o período é parcial, ou seja, as crianças permanecem na instituição apenas um período do dia. Já na municipal, as observaçóes foram alternadas entre o período da manhã e da tarde, tendo em vista que muitas crianças permanecem no CER em período integral: manhã e tarde. 


\section{Procedimento para a análise de informações}

O procedimento utilizado para a análise das observaçóes foi a análise de conteúdo. Segundo Bardin (1988, p. 38), “[...] a análise de conteúdo é um conjunto de técnicas de análise das comunicaçôes, que utiliza procedimentos sistemáticos e objetivos de descrição do conteúdo das mensagens”. A autora ainda destaca que o objetivo desta análise é a inferência de conhecimentos relativos às condiçóes de produção (ou, eventualmente, de recepção), e esta inferência recorre a indicadores (quantitativos ou não). Outro objetivo se refere ao fato de esta análise estabelecer uma correspondência entre o nível empírico e o teórico, de modo a assegurarmos que o corpo de hipóteses é verificado pelos dados do texto (BARDIN, 1988).

Bardin (1988, p. 30) também aponta duas funçôes da análise de conteúdo:

Uma função heurística: a análise de conteúdo enriquece a tentativa exploratória, aumenta a propensão à descoberta. É a análise de conteúdo "para ver o que dá". Uma função de administração de provas. Hipóteses sobre a forma de questóes ou de afirmaçôes provisórias servindo de diretrizes apelarão para o método de análise sistemática para serem verificadas no sentido de uma confirmação ou de uma informação. É a análise de conteúdo "para servir de prova”.

A análise de conteúdo organiza-se em diferentes polos cronológicos: a pré-análise, quando são feitas a leitura flutuante e a escolha dos documentos; a formulação das hipóteses e dos objetivos; a exploração do material e o tratamento dos resultados obtidos, e a interpretação (BARDIN, 1988).

Segundo Bardin (1988), tratar o material é codificá-lo. A codificação corresponde a uma transformação (efetuada segundo regras precisas) dos dados brutos do texto, transformação esta que, por recorte, agregação e enumeração, permite atingir uma representação do conteúdo ou de sua expressão, susceptível de esclarecer o analista acerca das características do texto, que podem servir de índices.

"A organização da codificação compreende três escolhas: o recorte (escolha das unidades); a enumeraçẫo (escolha das regras de contagem) e a classificação e a agregação (escolha das categorias)" (BARDIN, 1988, p. 104). 
Após a codificação do material, deve-se realizar sua categorização. "A categorização é uma operação de classificaçáo de elementos constitutivos de um conjunto, por diferenciação e, seguidamente, por reagrupamento segundo o gênero (analogia), com critérios previamente definidos" (BARDIN, 1988, p. 117-118). As categorias são rubricas ou classes que reúnem um grupo de elementos sob um título genérico. Esses agrupamentos são efetuados em razão dos caracteres comuns destes elementos. O critério de categorização pode ser semântico (categorias temáticas), sintático (verbos e advérbios), léxico (classificação das palavras segundo o seu sentido, com emparelhamento dos sinônimos e dos sentidos próximos) e expressivo (por exemplo, categorias que classificam as diversas perturbaçóes da linguagem).

A análise por categorias funciona por operaçóes de desmembramento do texto em unidades, em categorias segundo reagrupamentos analógicos. Entre as diferentes possibilidades de categorização, a investigação dos temas, ou análise temática, é rápida e eficaz na condição de se aplicar a discursos diretos e simples. (BARDIN, 1988, p. 153).

Em nossa análise, utilizamos o critério semântico, ou seja, definimos núcleos temáticos e posteriormente fizemos o recorte dos episódios presentes no texto e os agrupamos de acordo com o núcleo temático correspondente. A respeito do tema, Bardin (1988, p. 105) pontua que:

O tema é a unidade de significação que se liberta naturalmente de um texto analisado segundo certos critérios relativos à teoria que serve de guia à leitura [...] Fazer uma análise temática, consiste em descobrir os "núcleos de sentido" que compóem a comunicação e cuja presença, ou freqüência de aparição podem significar alguma coisa para o objetivo analítico escolhido.

Segundo Bardin (1988), existem várias técnicas para a análise de conteúdo, entre estas: a análise categorial, a análise de avaliação, a análise de enunciação, a análise de expressão, a análise de relaçôes e a análise de discurso. A técnica por nós utilizada será a análise categorial. 
A análise categorial pretende considerar a totalidade de um texto, passando-o pelo crivo da classificação e do recenseamento, segundo a frequência de presença ou ausência de itens de sentido. "É o método das categorias, espécie de gavetas ou rubricas significativas que permitem a classificação dos elementos de significação constitutivas, da mensagem" (BARDIN, 1988, p. 36-37).

Antes de iniciarmos a análise das práticas pedagógicas desenvolvidas nas instituiçóes pesquisadas, faremos uma caracterização das duas instituições com o intuito de apresentarmos os espaços e as estruturas destas.

\section{A caracterização das instituições pesquisadas}

A instituição municipal pesquisada atende crianças de zero a seis anos cujo horário de funcionamento estende-se das $7 \mathrm{~h} 30$ às $16 \mathrm{~h} 50$ de segunda a sexta-feira. Cabe ressaltar que as crianças que permanecem em período integral são atendidas por uma professora num período e pela agente educacional em outro. A estruturação das turmas segue na tabela abaixo:

Tabela 1 - Esboço da divisão por idade e turma das crianças de zero a três anos no CER

\begin{tabular}{|c|c|c|c|}
\hline Idade & Turma & $\begin{array}{c}\text { Número } \\
\text { de crianças }\end{array}$ & $\begin{array}{l}\text { Número de } \\
\text { educadoras }\end{array}$ \\
\hline $0-18$ meses & $1^{\circ}$ ano do CI Infantil (B1) & \multirow[b]{2}{*}{20} & \multirow{2}{*}{$\begin{array}{l}1 \text { berçarista para } \\
\text { cada grupo de } 5 \\
\text { crianças }\end{array}$} \\
\hline $\begin{array}{l}18 \text { meses }-2 \text { anos } \\
\text { e } 2 \text { meses }\end{array}$ & $2{ }^{\circ}$ ano do CI Infantil (B2) & & \\
\hline 26 meses -3 anos & $\begin{array}{l}-1^{\underline{a}} \text { classe do } 3^{\circ} \text { ano CI } 1 \\
\text { (manhã) } \\
-1^{\underline{a}} \text { classe do } 3^{\circ} \text { ano CI } 2 \\
\text { (tarde) }\end{array}$ & 20 & $\begin{array}{l}1 \text { professora e } 1 \\
\text { agente educacional }\end{array}$ \\
\hline
\end{tabular}

Fonte: Organizada pelas autoras.

O CER possui uma ampla área externa que é constituída por três tanques de areia com alguns brinquedos como escorregador, cilindros de concreto, etc.; uma área coberta com mesas no tamanho adequado ao alcance das crianças, além de um tanque de areia com uma casinha construída em alvenaria. Na parte interna, o CER possui um refeitório amplo, a sala da diretoria e mais seis salas. Destas, uma é ocupada pelo B1, outra pelo B2, uma pelo CI2 e as demais salas são distribuídas de acordo com o rodízio, que, segundo a Proposta Pedagógica do CER, é parte integrante do planejamento e consiste na divisão do CER em 
espaços diferentes utilizados por todos os educadores em tempos diferentes. Ainda nesse documento, consta que esse sistema de rodízio deverá ser elaborado por todos os educadores que utilizam os diferentes espaços do CER, devendo ser montado no início de cada ano letivo, além de revisto e reformulado sempre que necessário. Além disso, no documento está escrito que os educadores têm autonomia para modificar o seu rodízio, de acordo com as necessidades do grupo e as possibilidades, porém respeitando o espaço dos outros grupos. As salas que compóem o rodízio são: a sala estruturada, com mesas (uma para cada quatro crianças); quadro negro; armários que contêm os materiais pedagógicos, de uso pessoal e coletivo das crianças; a sala de multimeios, equipada com aparelho de som, videocassete, DVD, TV e demais recursos visuais (porém, sem carteiras); e a sala de recursos, com diversos materiais (brinquedos, livros, jogos, fantoches, fantasias, roupas de adultos, etc.).

A instituição particular oferece Educação Infantil (zero a seis anos) e Ensino Fundamental. O horário de funcionamento é das $7 \mathrm{~h} 10$ às $17 \mathrm{~h} 30$ de segunda a sexta-feira. Para a faixa etária pesquisada (zero a três anos), a instituição apresenta:

Tabela 2 - Esboço da divisão por idade e turma das crianças de zero a três anos na instituição particular

\begin{tabular}{c|c|c|c}
\hline Idade & Turma & Número de crianças & Número de educadoras \\
\hline $0-2$ anos & Berçário & 7 & 2 \\
\hline $2-3$ anos & Maternal & 9 & 1 \\
\hline
\end{tabular}

Fonte: Organizada pelas autoras.

Esta instituição funciona num local onde há uma casa e ampla área verde, com dois parques e diversas árvores. Um destes parques contém tanque de areia, e outro possui balanços e alguns brinquedos. Na casa, há salas de aula, a secretaria e a sala da diretora. Na parte externa, fica o refeitório. As salas de aula são pequenas e mal estruturadas. A sala do berçário não possui muitos brinquedos ou livros, e não há mesas. A educadora leva as crianças para realizarem atividades no refeitório onde há mesas e carteiras. $\mathrm{Na}$ sala do maternal, há mesas que agrupam as crianças em quatro, e existem alguns brinquedos, como quebra-cabeças, jogos e garrafas pet com cores diferentes, cada uma com uma letra escrita de tinta em seu exterior. Há também um 
quadro-negro e giz. Na parede, foram fixados um calendário e muitas colagens de reportagens de jornal e de produçóes das crianças.

\section{Os núcleos temáticos, o recorte e a análise dos episódios nas instituições de Educação Infantil pesquisadas}

Tendo como referencial a análise categorial proposta por Bardin (1988), realizamos inicialmente uma leitura flutuante das nossas notas de campo para que pudéssemos escolher as nossas categorias de análise, que denominamos núcleos temáticos. Foram definidos quatro núcleos temáticos: a) atividades didáticas $(\mathrm{AD})$, que englobam açóes planejadas pelo professor, a saber: atividades de registros gráficos, desenhos, colagens, registro de palavras, pinturas; atividades com formas geométricas, bem como atividades conjuntas com as crianças, como música e contação de histórias; b) atividades lúdicas (AL), que incluem as atividades relacionadas ao brincar; passeios, jogos, livres ou dirigidos desenvolvidos nos espaços da instituição; c) atividades de cuidado (AC), que correspondem às atividades relacionadas a cuidados pessoais, como: escovar os dentes, lavar as mãos, calçar sapatos, tomar banho, além de alimentação, sono e cuidados com a saúde; d) atividades disciplinares (Ad), as quais se referem às atividades relacionadas a puniçóes e castigos empregados às crianças pela não-realização de regras preestabelecidas pelas educadoras.

Posteriormente à definição destes núcleos, voltamos às nossas notas de campo e realizamos o recorte, para cada turma de crianças, dos episódios que se ajustavam em cada núcleo temático apresentado.

\section{Análise dos episódios da instituição municipal}

Iniciamos esta análise com a exposição do gráfico abaixo para facilitar a compreensão dos episódios em geral.

Com relação às atividades didáticas, temos maior ocorrência no CI1 com oito episódios, enquanto o CI2 apresenta seis, o B1 apenas um, e o B2 nenhum. O B1 apresenta treze episódios de atividades lúdicas, no CI1 temos onze, no B2 dez, e no CI2 sete. Acerca das atividades de cuidado, são vinte e nove episódios no CI1, vinte e três no B2, dezessete no B1, e treze no CI2. Notamos que, no que tange às atividades disciplinares, só há a incidência de um episódio no CI2, nas outras turmas estas atividades estão ausentes. 
Gráfico 1 - Número de episódios ocorridos em cada núcleo temático segundo cada turma na Instituição Municipal

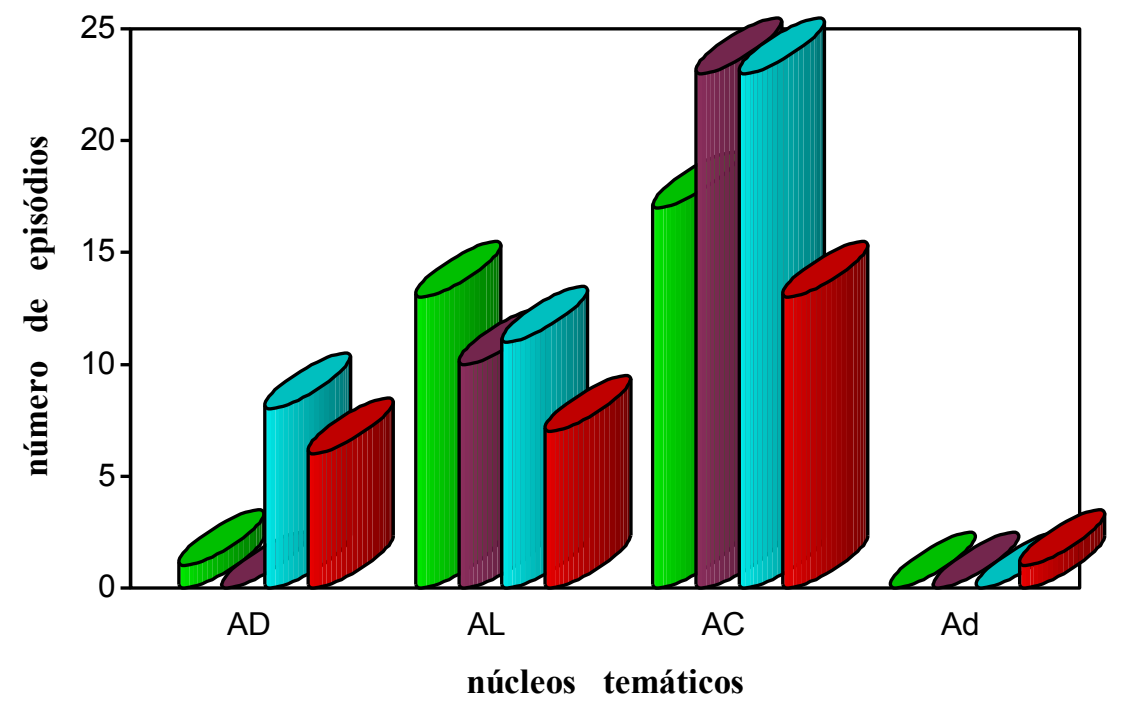

$\square \mathrm{B} 1 \mathrm{BB} 2 \mathrm{\square Cl} 1 \mathrm{\square Cl} 2$

Fonte: Dados coletados pelas autoras.

No que se refere às atividades didáticas, podemos notar uma relação diretamente proporcional entre a utilização e o crescimento numérico da faixa etária, isto é, quanto maior a idade, maior a aplicação de atividades didáticas. Em relação às atividades lúdicas, constatamos alta utilização em todas as turmas, sobretudo entre as crianças mais novas. Ao contrário das atividades didáticas, encontramos uma relação inversamente proporcional ao crescimento da idade, ou seja, quanto mais novas as crianças, maior o número de atividades lúdicas. Destacamos também que as atividades de cuidado apresentam uma alta ocorrência em todas as turmas, sendo maior no B2 e CI1. Isso é verificado principalmente porque estas turmas são atendidas em período integral, tempo suficiente para que as crianças tomem banho se alimentem em média cinco vezes e façam a higiene pessoal, como escovar os dentes e lavar as mãos, além do horário reservado ao repouso. Isto não acontece na turma do CI2, que apresentou menor ocorrência de atividades de cuidado, uma vez que o tempo 
das crianças é parcial. No B1, também há crianças em tempo parcial. Quanto às atividades disciplinares, presenciamos apenas uma ocorrência no CI2 que consideramos importante destacar, visto que uma açáo que deveria ser de cuidado foi conduzida pela educadora de forma punitiva mediante a falta de controle dos esfíncteres. Contudo, sabemos que esse processo é individual e gradativo, portanto, não tão rápido e simples como interpreta a professora que o conduziu, houve uma exposição da criança perante seus colegas de turma, e isso poderia e pode travar o processo de controle dos esfíncteres daquela criança, bem como causar problemas psíquicos futuros.

Em princípio, podemos destacar o protagonismo das crianças em seu processo educativo, visto que os episódios mostram que elas conduzem as atividades, isto é, as crianças direcionam as açóes, deixando claro que o papel do educador se resume a fazer a mediação, quando solicitado por elas. Também foi possível perceber a prioridade dos atos espontâneos nas atividades realizadas com as crianças, pois estas ficam soltas para fazerem as tarefas que considerarem mais adequadas, levando em consideração o seu tempo para o exercício da atividade.

Outra característica marcante nos episódios é o brincar, uma vez que notamos que as atividades lúdicas, em todas as turmas, são bem maiores que as atividades didáticas.

Não podemos deixar de salientar o alto número de episódios de cuidado, evidenciando o caráter recorrente ao assistencialismo táo discutido na Educaçáo Infantil. Por outro lado, se tivéssemos concomitantemente altos índices de atividades educativas poderíamos dizer que haveria a integração entre educar e cuidar. Porém, através dos episódios compreendemos que o cuidado é muito presente, e o educar chega até a ser ausente, como é o caso do B2, onde não houve o registro de nenhuma atividade didática.

A análise dos episódios nos permitiu entender que o conhecimento almejado é aquele construído entre educador e criança, com a ressalva de que esta centraliza o processo de aquisição de conhecimento, e o professor assessora quando solicitado.

\section{Análise dos episódios da instituição particular}

Assim como realizamos no item anterior com a instituição municipal, iniciaremos a análise discutindo o gráfico abaixo, que descreve a análise dos episódios da instituição particular. 
Gráfico 2 - Número de episódios ocorridos em cada núcleo temático segundo cada turma na Instituição Particular

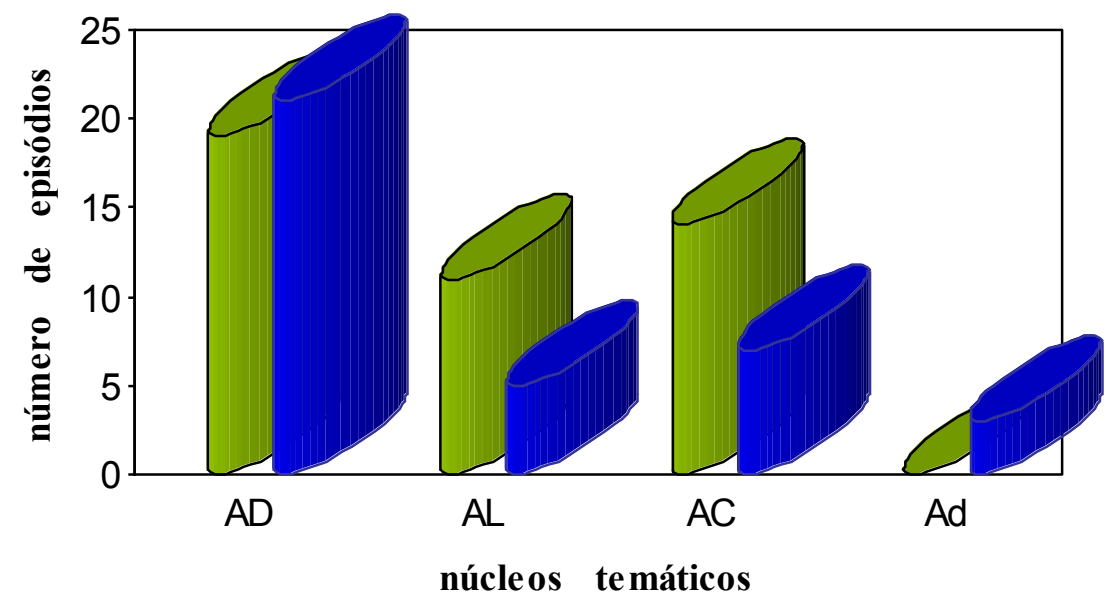

\section{$\square$ Berçário $\square$ Maternal}

Fonte: Dados coletados pelas autoras.

Quanto às atividades didáticas, verificamos maiores ocorrências no maternal e berçário, com vinte e um e dezenove episódios, respectivamente. Em relação às atividades lúdicas, estas são mais recorrentes no berçário, com onze episódios, e no maternal, com cinco.

Com relação às atividades de cuidado, foram quatorze episódios no berçário e sete no maternal. As atividades disciplinares não ocorreram no berçário, contudo verificamos três episódios no maternal.

Assim como na instituição municipal, constatamos que a frequência das atividades didáticas é diretamente proporcional ao aumento da idade. Já as atividades lúdicas ocorreram mais no berçário. Nesse caso, como na escola pública, temos uma relação inversamente proporcional, quanto menor a criança, maior o número de atividades lúdicas. O número de episódios relacionados ao cuidado corresponde ao dobro do que foi verificado no berçário do que no maternal, uma vez que as crianças de zero a dois anos necessitam de maiores cuidados relacionados à higiene, sono, alimentaçáo, 
banho do que as maiores, de dois a três anos. Outro fator é que as crianças do maternal sáo todas de tempo parcial, reduzindo as atividades de cuidado, como, por exemplo, o sono.

Não houve relato de episódios referentes a atividades disciplinares no berçário, todavia, no maternal ocorreram três episódios. Nesta turma, a educadora adota o método de recompensa-punição, no qual as crianças são recompensadas pela obediência. Na maioria das vezes, a recompensa está vinculada à realização de atividades lúdicas, como: andar de bicicleta e brincar no parque da escola. Ao contrário, aquelas desobedientes seriam punidas, por exemplo, permanecendo sentadas, enquanto as outras crianças brincam, por cerca de quinze minutos.

Quanto ao papel do educador, os episódios nos revelam que o processo de ensino-aprendizagem é conduzido pela educadora, e não pela criança. É a educadora quem direciona a aprendizagem, definindo as diretrizes do que será ensinado em sala de aula, ou seja, há uma intencionalidade no trabalho da educadora.

Desta forma, percebemos que há uma diferença entre as práticas educativas desenvolvidas na instituição particular e na municipal, porém isso náo significa que o ensino e, consequentemente, o desenvolvimento propiciado pela instituição particular seja o esperado ou possa se constituir em modelo a ser seguido. Posteriormente, veremos qual a concepção que está posta como pano de fundo destas práticas, refletindo sobre a concepção de desenvolvimento e ensino segundo o corpo teórico da Psicologia Histórico-Cultural.

\section{O desenvolvimento infantil na Psicologia Tradicional e na Psicologia Histórico-Cultural}

Mediante as informações anteriores, podemos destacar que as práticas educativas desenvolvidas nas instituições pesquisadas não promovem satisfatoriamente o desenvolvimento integral das crianças. Ao contrário, essas práticas apenas facilitam o desenvolvimento de aspectos biológicos, ou seja, a maturação de características consideradas inatas às crianças. Todavia, esse intento não satisfaz o interesse daqueles que estão em defesa de uma Educação Infantil que favoreça o desenvolvimento integral da criança em suas máximas potencialidades, pautada no ensino, na condução intencional do trabalho pedagógico a ser realizado pelo professor. Percebemos, também, uma 
fragmentação e naturalização da educação, além da negação do homem como ser histórico e social.

Desta forma, a visão de Educação Infantil percebida na análise das práticas educativas é herdeira de uma Psicologia Tradicional, que não propicia um contato mais aprofundado com toda a produção humana, impossibilitando a formação integral do indivíduo. Esta, segundo Tuleski (2004), carrega em si as marcas a-históricas e conservadoras da sociedade que lhe deu origem, visto que se institui como ciência no contexto histórico em que a burguesia se consolida no poder e se converte imediatamente ao reacionarismo. A autora também aponta que diversas correntes psicológicas permanecem herdeiras de suas raízes, caracterizando-se pelas mesmas contradiçôes e limites, em especial, por negar o homem como ser histórico.

Bock (2004) salienta que a Psicologia Tradicional traz concepçóes universalizantes e naturalizantes da subjetividade, nas quais o homem e seu mundo psíquico são pensados de forma natural, com capacidades e características da espécie. Logo, o homem é responsável pelo seu sucesso ou insucesso, e o desenvolvimento pode ocorrer caso o indivíduo seja inserido num meio adequado.

Podemos perceber na Psicologia Tradicional cisóes, tais como: razão versus emoção, objetividade versus subjetividade, que tem comprometido a "[...] apreensão gnosiológica do indivíduo real e concreto, alimentando equívocos no tratamento dispensado ao psiquismo humano de nefastas implicaçóes pedagógicas" (MARTINS, 2007, p. 118). Ademais, Tanamachi (2007) afirma que diversos estudos, realizados por várias correntes de pensamento que se desenvolveram na Psicologia ocidental, tais como analisadas por Vigotsky e o seu grupo, apresentam visóes reducionistas sobre o fenômeno humano e, consequentemente, não respondem à realidade do ser humano em sua existência concreta, social e historicamente determinada.

Segundo Vigotsky (1995), a Psicologia Tradicional preocupava-se com a criança e o com o desenvolvimento de suas funçóes psíquicas in abstracto, ou seja, desconsiderando o seu meio social e cultural; suas formas de pensamento, concepçóes e ideias produzidas historicamente e predominantes nesse meio. A crítica que Vigotsky (2001) fazia à velha Psicologia era direcionada à forma como esta considerava os processos psíquicos superiores, uma vez que estes eram tratados como soma ou cadeia de processos elementares. Para Vigotsky (1996), a tarefa fundamental da análise em Psicologia não é fragmentar, mas 
evidenciar o conjunto psicológico integral de determinados traços e momentos que conservam a prioridade do todo.

De acordo com Tuleski (2002), a superação da velha Psicologia só seria possível com a elaboraçáo de uma nova Psicologia sustentada numa perspectiva histórica da relação entre homem e natureza, de modo que o homem fosse o produto e produtor de si e da própria natureza. Isso significaria a superação das relaçóes mecânicas, empíricas e simples entre os fenômenos, por uma nova compreensão do homem como um ser complexo e dinâmico. Compartilhando dessa ideia, Saviani (2004) destaca que é necessário conhecer o indivíduo concreto, uma vez que o indivíduo empírico é o imediatamente observável, apreendido por definiçôes exteriores correspondentes à situação empírica imediata, porém, o indivíduo concreto é a síntese das múltiplas determinações, apreendido à luz de sua natureza histórico-social.

Este reducionismo operado por uma visão naturalizante do desenvolvimento infantil leva o trabalho com crianças menores de três anos a reduzir-se ao cuidado com o corpo e ao espontaneísmo acalentado pela crença de que brincar é algo natural a essa criança. Então, deixemos as crianças brincarem livremente e cuidemos de seu corpo. Ao mesmo tempo, assim que ela se torna "capaz" de falar e andar, deixemos o lúdico de lado e passemos às atividades didático-pedagógicas intensas. Extremos que não contribuem para o desenvolvimento integral desta criança, mas que, ao mesmo tempo, revelam uma visão linear e naturalizada do desenvolvimento infantil.

Uma alternativa seria a Psicologia Histórico-Cultural, que, segundo Bozhovich (1976), apresenta como tarefa investigar as particularidades psicológicas da criança segundo sua idade, que náo se limitam à característica dos processos psíquicos isolados, mas que revelam a estrutura da personalidade integral da criança em seu processo de formação e desenvolvimento. O mesmo é visto em Elkonin (1969), acrescentando que as particularidades psicológicas da criança de qualquer idade se formam se submetendo às leis essenciais do desenvolvimento de sua psique na dependência das condiçôes concretas de sua vida, atividade e educação.

Vale ressaltar que a Psicologia Histórico-Cultural surgiu no início do século XX na ex-União Soviética (URSS), no contexto da Rússia pós-revolucionária (DAVIDOV; SHUARE, 1987). Esta corrente tem como principais referências Liev Semiónovich Vigotsky (1896-1934), Alexis Nikoláevich Leontiev (1903-1979) e Alexander Románovich Luria (1902-1977), que, junto com 
representantes como Daniíl Borísovich Elkonin (1904-1984), Vasili Vasílievich Davidov (1930-1998), Alexandr Vladimirovich Zaporozhets (1905-1981), Piotr Iakovlevich Galperin (1902-1988) e Lidia Ilínichna Bozhovich (1908-1981) compóem a chamada Escola de Vigotski (DAVIDOV; SHUARE, 1987).

De acordo com Pasqualini (2006, p. 117), Vigotski, Leontiev e Elkonin concebiam o desenvolvimento infantil como fenômeno histórico e dialético, que "[...] não é determinado por leis naturais universais, mas encontra-se intimamente ligado às condiçôes objetivas da organização social e não se desenrola de forma meramente linear, progressiva e evolutiva, mas compreende saltos qualitativos, involuçóes e rupturas". Ou seja, passamos de uma visão linear e naturalizante do desenvolvimento para compreendê-lo como uma espiral ascendente marcada por revoluçóes. O desenvolvimento passa a ser visto como um processo longo e intimamente ligado às suas condiçóes sócio-históricas e culturais de inserção na sociedade.

Cabe salientar que o desenvolvimento psíquico das crianças acontece no processo de educação e ensino realizado pelos adultos, que organizam a vida da criança, criando condiçôes determinadas para seu desenvolvimento e lhe transmitindo a experiência social acumulada pela humanidade no período precedente de sua história. Os adultos são os portadores desta experiência social. Segundo Elkonin (1969), através dos adultos a criança assimila um amplo círculo de conhecimentos adquiridos pelas geraçóes precedentes, aprende as habilidades elaboradas socialmente e as formas de conduta que se têm criado na sociedade. À medida que assimilam a experiência social, se formam nas crianças distintas capacidades. Os adultos e, em especial, o professor que atua com a criança pequena são os parteiros da criança para sua vida em sociedade e para a concretização tanto do desenvolvimento de sua psique quanto de todo o seu aparato biológico.

O ingresso na escola muda de modo radical a situação da criança na sociedade, transforma fundamentalmente todo seu sistema de relaçóes mútuas com os adultos e com outras crianças. A criança começa uma atividade séria, de significação social. Nesse momento, ela deve assimilar um conjunto determinado de conhecimentos e hábitos, e tem que aprender de uma maneira sistemática, quando isto lhe foi exigido. De acordo com Elkonin (1969), a criança começa a apresentar relaçóes sérias com o mestre e com o conjunto de estudantes de sua classe e, em parte, com toda a escola. A forma como o escolar realiza suas obrigaçóes determina sua situação na escola, no conjunto da classe, na 
família e também suas relações mútuas com as demais crianças e adultos. Suas relaçóes concretas com os que lhe rodeiam começam a estar determinadas pelos resultados de sua atividade, pela maneira como cumpre suas obrigaçôes escolares, de membro do conjunto de sua classe e de membro da família.

Consideramos que, ao entrar na escola, a criança, como apresentado por Luria (2006), possui suas próprias habilidades culturais, contudo, devemos considerar que este equipamento é primitivo e arcaico: "[...] ele não foi forjado pela influência sistemática do ambiente pedagógico, mas pelas próprias tentativas primitivas feitas pela criança para lidar, por si mesma, com tarefas culturais" (LURIA, 2006, p. 111). Além disso, acrescentamos que "[...] o desenvolvimento psicológico dos indivíduos segue um caminho de 'herança social' (Engels) ou um caminho de 'apropriação' (Marx) de experiência social" (ZAPOROZHETS; ELKONIN, 1971, p. xi, tradução nossa). Apontamos, também, que o estudo do desenvolvimento infantil significa "[...] estudar a passagem da criança de um período evolutivo a outro e a mudança de sua personalidade dentro de cada período evolutivo que tem lugar em condiçóes histórico-sociais concretas" (ELKONIN, 1987, p. 106).

Nâo podemos deixar de mencionar que partilhamos das concepçôes de Saviani (2005) acerca da função da escola e do papel do professor neste processo.

Segundo Saviani (2005), a educação situa-se na categoria do trabalho não material, e nesta devemos distinguir duas modalidades. A primeira diz respeito àquelas atividades em que o produto se separa do produtor, como nos livros e objetos artísticos. A segunda refere-se às atividades em que o produto não se separa do ato de produção. Nesse caso, "[...] o ato de produção e o ato de consumo imbricam-se” (SAVIANI, 2005, p. 12). É nessa modalidade do trabalho não material que se situa a educação.

O trabalho educativo, de acordo com Saviani (2005), é o ato de produzir, direta e intencionalmente, em cada indivíduo singular, a humanidade que é produzida histórica e coletivamente pelo conjunto dos homens. Sendo assim, o objeto da educação refere-se, primeiro, à identificação dos elementos culturais que precisam ser assimilados pelos indivíduos da espécie humana para que estes se tornem humanos e, posterior e concomitantemente, à descoberta das formas mais adequadas para atingir esse objetivo. Quanto ao primeiro aspecto, "[...] trata-se de distinguir entre o essencial e o acidental, o principal e o secundário, o fundamental e o acessório" (SAVIANI, 2005, p. 13). O segundo aspecto relaciona-se à "[...] organização dos meios (conteúdos, espaço, tempo 
e procedimento) através dos quais, progressivamente, cada indivíduo singular realize, na forma de segunda natureza, a humanidade produzida historicamente" (SAVIANI, 2005, p. 14).

Portanto, quando pensamos a criança pequena e sua educação a partir da Psicologia Histórico Cultural, não podemos nos furtar a destacar o papel que o adulto-professor tem para com o seu desenvolvimento, ele não deve esperá-lo, mas deve provocá-lo. E a forma de fazê-lo deve estar pedagogicamente adequada à faixa etária que está a ser atendida. Esta reflexão a respeito de quem é a criança e como esta se desenvolve do ponto de vista bio-psico-social é o primeiro passo para que se consiga quebrar com os dois extremos presenciados nesta pesquisa: espontaneísmo total e o diretivismo por vezes inadequado do trabalho a ser realizado. Consequentemente, se aprimoramos o entendimento da importância do papel do adulto como aquele que provoca desenvolvimento, essencialmente no trabalho com crianças menores de três anos, a instituição que atende estas crianças deixa de ser vista como um simples local para assistência. O profissional que ali atua deixa de ser o mero cuidador. Temos, então, o professor que deve possuir uma gama de conhecimentos a respeito da criança e, também a respeito de metodologia de ensino e temos uma instituiçáo que se volta por meio do ensino, da educação, a objetivar o desenvolvimento integral das crianças.

\section{Considerações finais}

Neste artigo, buscamos analisar o impacto que a concepçâo de desenvolvimento infantil traz para a prática pedagógica com crianças de zero a três anos, tendo como referencial teórico a Psicologia Histórico-Cultural. Acreditamos que, a partir deste estudo, podemos pensar em uma proposta curricular tendo o ensino como eixo norteador do trabalho docente.

Constatamos, por meio das observaçōes realizadas nas instituições de Educação Infantil, que o trabalho docente ainda está mais voltado para questóes assistenciais do que educativas, e quando as atividades educativas aparecem, muitas vezes são inadequadas ou até mesmo empobrecidas diante das possibilidades de trabalho existentes para com esta criança pequena. Ressaltamos que nossa visão de ensino perpassa o trabalho educativo como exposto anteriormente (SAVIANI, 2005). Não excluímos o cuidar, porém trabalhamos com este de forma diferenciada, uma vez que o cuidar "[...] significa também ensinar, produzir o humano no próprio corpo da criança e sua relação 
com ele, passando pela alimentação, pelo andar, movimentar-se etc." (ARCE, 2007, p. 32).

A pesquisa de campo realizada nos permitiu apreender, na instituição municipal, que, da forma como está posta a educação infantil, as crianças não encontram na escola um local para se desenvolverem integralmente, mas sim um local de espera. Espera esta que, pelo vazio pedagógico que a acompanha, acaba por ser palco de reprodução de práticas espontaneístas, perpetuaçóes do senso comum. Neste ambiente, reforçam-se crenças, preconceitos, o terreno fertiliza-se com a falta do conhecimento com uma série de slogans, como por exemplo, a recorrente ideia de que criança precisa comer doce, refrigerante é algo também necessário para a felicidade infantil, etc. Perde-se a oportunidade ímpar de transformar esta escola em espaço de aprendizagem, deixa-se jogada na ignorância esta profissional. Ganha destaque, então, o cuidado com o corpo, mas mesmo este se empobrece e reduz-se ao trocar, limpar, lavar mecânicos. E a observação da realização dos procedimentos de cuidado com o corpo acaba por assemelhar-se com a produção fabril em série. A profissional torna-se uma mera cuidadora, à espera de, à espera de...

Em tempos de precarização do trabalho docente, como muito bem exposto nos trabalhos de Sampaio e Marin (2004) e Kuenzer (1999), o impacto desta ausência de objetivos educativos empurra esta profissional e a encarcera no amadorismo, sendo possível até colocar-se em dúvida a necessidade de uma formação em nível de terceiro grau para ela. $\mathrm{O}$ resultado, o sentem a criança e esta professora, materializado na desvalorização deste nível de atendimento pela sociedade e pelo poder público.

Faz-se, portanto, imprescindível que pensemos a Educação Infantil como a articulação entre uma tríade: formação docente, práticas educativas intencionais e políticas públicas, tendo como suporte para a educação das crianças pequenas o papel do ensino. Kuenzer (1999) apresenta que a função do educador é ensinar, transmitir o saber sistematizado, e para isso é preciso que haja intencionalidade no trabalho do professor. Além disso, é essencial que esse profissional seja valorizado, pois na prática percebemos que o trabalho docente é desenvolvido ante, muitas vezes, condiçóes materiais impróprias, ou seja, há uma precarização do trabalho docente, como apontado por Sampaio e Marin (2004). Desta forma, podemos dizer que a valorização do educador é fundamental. Consideramos que se faz necessário pensarmos nesse profissional como um intelectual; um profissional responsável pelo desenvolvimento desta criança. 
Por outro lado, a instituiçấo privada de ensino nos traz outra realidade, que em princípio parece muito distinta da instituição pública, mas não o é. A distinção aparente que salta aos olhos se transfigura na intencionalidade da professora, que conduz o processo, provoca desenvolvimento. Mas, se analisarmos com mais detalhamento, encontraremos também lá uma incompreensão das possibilidades desta criança e até mesmo do papel que a professora possui no desenvolvimento infantil. Sem falarmos do desconhecimento das questóes teórico-metodológicas, apenas para exemplificarmos, observamos trabalhos conduzidos de formas distintas nestas instituiçóes, entretanto, ambos encontravam-se amparados na teoria construtivista. Como isso é possível? Teorias, metodologias são etiquetas presas na capa que reveste as escolas, sendo incompreendidas e desconhecidas, e acabam por referendar conhecimentos presentes no cotidiano dos indivíduos. A intencionalidade presente na escola privada acaba por estimular as crianças, mas revela uma pobreza quanto ao objetivo que a impulsiona, pois este se reduz a mostrar resultados, indicar aos pais que esta criança será alfabetizada. A partir deste ponto, tudo vale, inclusive o "apostilamento".

Os estudos realizados pelos teóricos da Psicologia Histórico-Cultural nos desafiam a ir além das práticas que hoje temos nas escolas, mas para isso precisamos nos apropriar dos conhecimentos produzidos em várias áreas para pensar a criança e o trabalho pedagógico: como ignorar os resultados das pesquisas no campo das Neurociências, da Pediatria, da Educação Física, as discussōes efetuadas a respeito do ensino de Literatura Infantil, Matemática, Física, Química, Biologia, Língua Portuguesa, Geografia, Música, Artes Plásticas e Gráficas, etc.? Destacamos estas áreas, porque a criança também é objeto de muitos destes pesquisadores, seus trabalhos têm muito a nos dizer. Conteúdos advindos destas áreas de conhecimento estarão presentes na exploração, no conhecimento do mundo pela criança. Consequentemente, o professor deve dominá-los para ser capaz de trabalhá-los de forma adequada a esta faixa etária. Ao mesmo tempo, como ignorar o conhecimento que já temos acumulado no campo da Pedagogia a respeito do trabalho teórico-metodológico com crianças? Esta pesquisa nos apontou que o compasso da "espera" é o compasso do vazio, vazio do conhecimento.

Diante do exposto, problematizamos que pensar a concepção de infância, trabalho docente e aquisição de conhecimento e, consequentemente, desenvolvimento considerando a Psicologia Histórico-Cultural demanda, entre outras coisas: clareza do papel educacional da instituição de Educaçáo 
Infantil; formação docente; interdisciplinaridade. Ou seja, é necessário revolucionar a forma como olhamos, pensamos e definimos o que é a criança e seu desenvolvimento, quem é o professor de Educação Infantil e como deve ser feita a sua formação.

\section{Notas}

1 Esta pesquisa foi realizada de 2006 a 2008 na Faculdade de Ciências e Letras da Unesp/Araraquara, com financiamento inicialmente da Capes de 2006 a 2007 e, posteriormente, da FAPESP de 2007 a 2008 (SILVA, 2008).

2 Denominação atribuída pela Secretaria Municipal de Educação às instituiçôes que atendem crianças de zero a três anos.

\section{REFERÊNCIAS}

ARCE, Alessandra. O Referencial Curricular Nacional para a Educação Infantil e o espontaneísmo: (re)colocando o ensino como eixo norteador do trabalho. In: ARCE, Alessandra; MARTINS, Lígia Márcia. (Org.). Quem tem medo de ensinar na Educação Infantil? Em defesa do ato de ensinar. Campinas: Alínea, 2007. p. 13-36.

BARDIN, Laurence. Análise de Conteúdo. Lisboa: Ediçōes 70, 1988.

BOCK, Ana Mercês Bahia. A perspectiva histórica da subjetividade: uma exigência para la psicologia atual. Psicología para a América Latina, [S. 1.], n. 1, fev. 2004. Disponível em: <http://psicolatina.org/Uno/a_perspectiva_ historica.pdf $>$. Acesso em: 20 fev. 2008.

BOGDAN, Robert C.; BIKLEN, Sari Knopp. Investigação Qualitativa em Educação: uma introdução à teoria e aos métodos. Porto: Porto Editora, 1994.

BOZHOVICH, Lidia Ilínichna. La personalidad y su formación en la edad infantil: investigaciones psicológicas. Tradução de Toste Muñiz. La Habana: Pueblo y Educación, 1976.

DAVIDOV, Vasili Vasílievich; SHUARE, Marta. (Org.). La Psicología Evolutiva y Pedagógica en la URSS: antología. Moscú: Progreso, 1987. 
ELKONIN, Daniíl Borísovich. Desarrollo psíquico de los niños. In: SMIRNOV, Anatolii Aleksandrovich (Org.). Psicología. 3. ed. Tradução de Florencio Villa Landa. México: Grijalbo, 1969. p. 493-560.

ELKONIN, Daniíl Borísovich. Sobre el problema de la periodización del desarrollo psíquico en la infancia. In: DAVIDOV, Vasili Vasílievich; SHUARE, Marta. (Org.). La Psicología Evolutiva y Pedagógica en la URSS: antología. Moscú: Progreso, 1987. p. 104-124.

GARIBOLDI, Antonio. O dia-a-dia educativo em uma pré-escola. In: BECCHI, Egle; BONDIOLI, Anna (Org.). Avaliando a pré-escola: uma trajetória de formação de professoras. Tradução de Fernanda Landucci Ortale e Ilse Carlos de Freitas. Campinas: Autores Associados, 2003. p. 37-56.

KUENZER, Acacia Zeneida. As políticas de formação: a constituição da identidade do professor sobrante. Educação e Sociedade, Campinas, ano XX, n. 68, p. 163-183, dez. 1999.

LEONTIEV, Alexis N. O desenvolvimento do psiquismo. Lisboa: Livros Horizonte, 1978.

LURIA, Alexander R. A psicologia experimental e o desenvolvimento infantil. In: VIGOTSKY, Lev Semenovitch; LURIA, Alexander R; LEONTIEV, Alexis N. Linguagem, desenvolvimento e aprendizagem. Tradução de Maria da Penha Villalobos. São Paulo: Ícone, 2006. p. 85-102.

MARTINS, Lígia Márcia Algumas reflexōes sobre o desenvolvimento omnilateral dos educandos. In: MEIRA, Maria Eugênia M.; FACCI, Marilda Gonçalves Dias (Org.). Psicologia Histórico-Cultural: contribuiçóes para o encontro entre a subjetividade e a educação. São Paulo: Casa do Psicólogo, 2007. p. 117-134.

PASQUALINI. Juliana Campregher. Contribuiçōes da Psicologia HistóricoCultural para a educação escolar de crianças de 0 a 6 anos: desenvolvimento infantil e ensino em Vigotski, Leontiev e Elkonin. 2006. 205 f. Dissertação (Mestrado em Educação Escolar) - Faculdade de Filosofia, Ciências e Letras, Universidade Estadual Paulista, Araraquara, SP: 2006.

SAMPAIO, Maria das Mercês Ferreira; MARIN, Alda Junqueira.

Precarização do trabalho docente e seus efeitos sobre as práticas curriculares. Educação e Sociedade, Campinas, v. 25, n. 89, p. 1203-1226, set./dez. 2004. 
SAVIANI, Demerval. Perspectiva marxiana do problema subjetividadeintersubjetividade. In: DUARTE, Newton (Org.). Critica ao fetichismo da individualidade. Campinas: Autores Associados, 2004. p. 21-52.

SAVIANI, Demerval. Pedagogia Histórico-Crítica: primeiras aproximaçôes. 9. ed. Campinas: Autores Associados, 2005. (Coleção Educação Contemporânea).

SILVA, Janaina Cassiano. Práticas educativas: a relação entre cuidar e educar e a promoção do desenvolvimento infantil à luz da Psicologia HistóricoCultural. 2008. 214 f. Dissertação (Mestrado em Educação Escolar) Faculdade de Filosofia, Ciências e Letras, Universidade Estadual Paulista, Araraquara, SP, 2008.

TANAMACHI, Elenita de. Ricio. A Psicologia no contexto do materialismo histórico dialético: elementos para compreender a Psicologia HistóricoCultural. In: MEIRA, Maria Eugênia M.; FACCI, Marilda Gonçalves Dias (Org.). Psicologia Histórico-Cultural: contribuiçóes para o encontro entre a subjetividade e a educação. São Paulo: Casa do Psicólogo, 2007. p. 63-92.

TULESKI, Silvana Calvo. Reflexões sobre a gênese da Psicologia Científica. In: DUARTE, Newton (Org.). Critica ao fetichismo da individualidade. Campinas: Autores Associados, 2004. p. 121-143.

TULESKI, Silvana Calvo. Vygotski: a construção de uma psicologia marxista. Maringá: Edum, 2002.

VIGOTSKY, Lev Semenovitch. Obras escogidas. Madrid: Visor, 1995. Tomo III.

VIGOTSKY, Lev Semenovitch. Obras escogidas. Madrid: Visor, 1996. Tomo IV.

VIGOTSKY, Lev Semenovitch. A construção do pensamento e da linguagem. Traduçáo de Paulo Bezerra. São Paulo: Martins Fontes, 2001.

ZAPOROZHETS, Alexandr Vladímirovich; ELKONIN, Daniíl Borísovich (Ed.) The psychology of preschool children. Tradução de John Shybut e Seymore Simon. Massachusetts: MIT Press, 1971. 
El impacto de las concepciones del desenvolvimiento infantil en las prácticas pedagógicas en las aulas para niños menores de tres años

\section{Resumen}

Este artículo analiza el impacto que la concepción del desarrollo infantil trae para la práctica pedagógica con los niños de cero a tres anos a la luz de la Psicología Histórico-Cultural. Para eso, traeremos los resultados de una investigación que estudió si las acciones educativas promocionan el cuidado y el educar. El trabajo se subdivide en tres partes, una dedicada a la presentación de la metodología y características de las instituciones, otra para el análisis de las prácticas pedagógicas, y la última destinada a la reflexión de concepción del desarrollo que contienen esas prácticas a la luz de la Psicología Histórico-Cultural. Las prácticas educativas desarrolladas en las instituciones investigadas apenas esperan el desarrollo considerado natural de los niños y niñas, apartándose de una educación infantil que favorezca su crecimiento integral en los valores máximos de su potencial, por medio de la enseńanza como una de las maneras intencionales de promoverlo.

Palabras claves: Prácticas educativas. Desarrollo infantil. Psicología histórico socio.

\section{The impact of child development concepts in pedagogical practices in classrooms for children under three}

\section{Abstract}

This article analyzes the impact that the concept of child development has for pedagogical practices with children three years old and younger, from the perspective of historicalcultural psychology. It presents the results of a study that investigated if the educational actions promote care and education, an essential association for the promotion of psychological development of children three and younger. To facilitate the study, we divide the work in three parts, one that presents the methodology and characterization of the institutions, another that analyzes the pedagogical practices and one that reflects on the concept of development found in these practices from the perspective of historic-cultural psychology. The educational practices undertaken at the institutions studied merely await the development considered natural for children, not adopting practices that encourage the integral development of children to their maximum potential by using teaching to promote this potential.

Keywords: Early childhood education. Child development. Socio-historical psychology. 


\title{
Janaina Cassiano Silva
}

E-mail: janacassiano@hotmail.com

\author{
Alessandra Arce Hai \\ E-mail: alessandra.arce@gmail.com
}

Recebido em: 7/3/2012

Versão final recebida em: 9/10/2012 